\title{
Recurrent orbital bone sub-periosteal hematoma in sickle cell disease: a case study
}

\author{
Abdulhamid Alghamdi
}

\begin{abstract}
Background: Sickle cell disease is a common inherited hemoglobinopathy and is associated with high morbidity and mortality. Vaso-occlusive crises commonly occur in individuals with SCD that results in high morbidity due to end-organ ischemia and infarction. These include splenic infarction, pulmonary involvement, acute chest syndrome, and orbital compression syndrome. Ocular manifestations of SCD include anterior segment ischemia, secondary glaucoma, angoid streaks, retinopathy, and retinal artery occlusion. Commonly reported causes for the incidence of sickle cell disease are extreme temperatures, wind speed, and rainfall. This study has conducted an investigation of recurrent orbital bone sub-periosteal hematoma in a sickle cell patient that was exposed to high altitude areas.

Case presentation: A 12-year-old boy with SCD developed a recurrent sudden periorbital pain and swelling during a visit to high altitude area. The family reported two similar attacks previously. The patient recovered completely with timely initiated conservative treatment. The case study is about homozygous SCD with previous history of similar attack of painful periorbital swelling that resolved after conservative management. This condition was associated with proptosis, diplopia, and restriction of eye movement. Magnetic resonance imaging of the orbits showed right orbital roof subperiosteal mass adjacent to the orbital wall, which was identified as a subperiosteal haematoma, inducing proptosis. The patient was discharged after 7 days with follow up.

Conclusions: Infarction of orbital bones during vaso-occlusive crises in SCD presented acutely with a rapidly progressive painful periorbital swelling. Hematomas frequently complicate the condition, along with the inflammatory swelling that may lead to the orbital compression syndrome. The condition is sight-threatening and necessitates prompt diagnosis along with appropriate management. This condition mandates prompt initiation of conservative treatment and close monitoring of the optic nerve functions to prevent permanent visual loss in young patients.
\end{abstract}

Keywords: High altitude, Orbital bone infarction, Orbital bone sub-periosteal hematoma, Orbital compression, Proptosis, SCD

\section{Background}

Sickle Cell Disease (SCD) is the most commonly inherited hemoglobinopathy worldwide and has resulted in the increase of global health burden [1]. SCD is an autosomal recessive disorder, characterized by production of abnormal hemoglobin $\mathrm{S}$, and is associated with high morbidity and mortality and is a relatively common genetic disorder across the world [2]. A pre-dominant

Correspondence: drghamdieye@hotmail.com

Department Of Ophthalmology, Faculty of Medicine, Taif University, Taif, Saudi Arabia feature of SCD is the occurrence of vaso-occlusive crises. A vaso-occlusive crisis affects all organ systems and are responsible for high morbidity and early mortality due to end-organ ischemia and infarction. These conditions are combined with the downstream effects of hemolysis due to red blood cell sickling. The clinical presentation of the end-organ vaso-occlusive crisis may mimic many clinical conditions, which creates a diagnostic dilemma. Recent reports of end-organ ischemia include splenic infarction [3], pulmonary involvement, acute chest syndrome [4], and orbital compression syndrome $[5,6]$. Ocular manifestations of SCD include anterior segment

(c) The Author(s). 2018 Open Access This article is distributed under the terms of the Creative Commons Attribution 4.0 International License (http://creativecommons.org/licenses/by/4.0/), which permits unrestricted use, distribution, and 
ischemia, secondary glaucoma, angoid streaks, retinopathy, and retinal artery occlusion. Autoinfarction of the orbital bones has been reported rarely. It can lead to acute proptosis, periorbital pain, limited motility, potentially compressive optic neuropathy, and orbital compression syndrome (OCS) $[7,8]$.

Commonly reported causes for the incidence of SCD are inclusive of extreme temperatures, wind speed, and rainfall [9]. It was discussed that these reported environmental factors significantly predispose sickle cell patients to acute vaso-occlusive crises. Although, a few studies have highlighted the relatively higher incidence of SCD in individuals living in high-altitude or mountainous areas [10]; the role that high altitude plays in increasing the risk of incidence of sickling cell crises has not yet been heavily explored. Earlier studies have highlighted cases of sickling cell crisis incidence in individuals flying at high-altitude areas in unpressurized aircrafts [11]. The incidence of altitude-induced hypoxemia leading to painful sickling crises was explored in an additional study that suggested that there was high risk presented to sickle cell patients when residing in high-mountainous regions [12]. This finding was corroborated by additional studies that highlighted the higher incidence of splenic infections in sickle cell patients following altitude-induced hypoxia [13]. However, the link between other types of infarction in sickle cell patients and high altitudes has not yet been established. Therefore, this study has conducted an investigation of recurrent orbital bone sub-periosteal hematoma in a sickle cell patient that was exposed to high altitude areas.

\section{Case presentation}

A 12-year-old boy with SCD was presented with fever, periocular pain, and diplopia after returning from Taif, Jeddah. Taif (means "encompassing") is located in the Hejaz Mountains of Saudi Arabia. It is considered as a high-altitude area because it is $6000 \mathrm{ft}$ above the sea level [14]. The patient had a previous history of similar attacks that resolved after conservative management at another hospital in the same city few years ago (Fig. 1).

On admission, the patient looked sick, drowsy, and pale. The temperature of patient was $38.2{ }^{\circ} \mathrm{C}$, heart rate was $115 / \mathrm{min}$, respiratory rate was $25 / \mathrm{min}$, blood pressure was $100 / 65$, and oxygen saturation was $90 \%$ on room air. The patient weighted $38 \mathrm{~kg}$. Ocular examination showed right eyelid edema, peri-ocular soft tissue swelling, proptosis, and limitation in elevation of the right eye. On admission, the visual acuity of right eye was 20/30 and left eye was $20 / 20$. Color vision was evaluated using the color plates that came out to be normal. The pupils were equal in size and reactive to light. Swinging light Reflex showed normal reaction of both pupils. There was no afferent pupillary light reflex defect (APD). The intra-ocular pressure was normal in both eyes. Fundus examination revealed normal
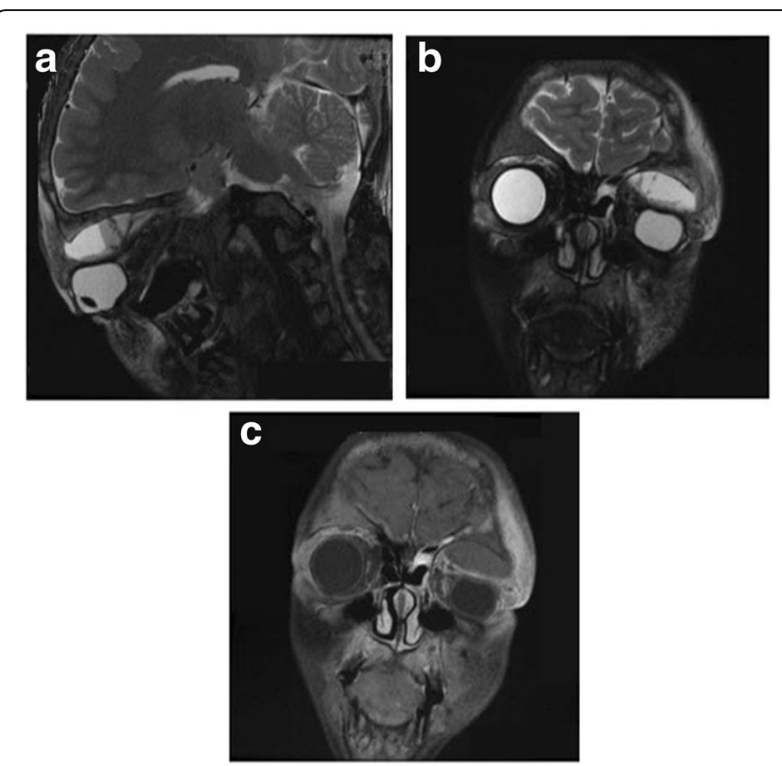

Fig. 1 a Coronal T2 Fat Suppression; (b) Sagittal T2 Fat Suppression; (c) Coronal T1Fat Suppression

disc, blood vessels, and macula. A complete systemic evaluation was conducted.

The systemic evaluation revealed hemolytic anemia, thrombocytopenia, stable coagulation profile, and negative blood culture. Laboratory results showed hemoglobin level of $89 \mathrm{~g} / \mathrm{L}$, mean cell volume was $84.2 \mathrm{FL}$, white blood cell count was $24.04 \times 109 / \mathrm{L}$ with neutrophils 21.81X109/L, and mean platelets volume 10.30 FL. Serum bilirubin was measured to be $95.5 \mathrm{mmol} / \mathrm{L}$, albumin was $26 \mathrm{~g} / \mathrm{L}$, blood urea was $3.8 \mathrm{mmol} / \mathrm{L}$, and serum creatinine was $39 \mathrm{mmol} / \mathrm{L}$. The erythrocyte sedimentation rate was $40 \mathrm{~mm} / \mathrm{h}$ (normal $<15 \mathrm{~mm} / \mathrm{h}$ ), and C-reactive protein was $8.2 \mathrm{mg} / \mathrm{dL}$ (normal $<0.5 \mathrm{mg} / \mathrm{dL}$ ) (Table 1 ).

The coagulation parameters revealed a prothrombin time (PT) of $14 \mathrm{~S}$ (normal 10-12.8), International Normalization Ratio (INR) 1.2 (normal 0.9-1.2) and activated partial prothrombin time (aPTT) 33.4 S (normal

Table 1 Summary of lab results

\begin{tabular}{llll}
\hline Test & Result & Unit & N. Range \\
\hline White Blood Cell Count & 24.04 & $\times 10^{9} / \mathrm{L}$ & $4-10$ \\
Neutrophils Count & 21.81 & $\times 10^{9} / \mathrm{L}$ & $2-9$ \\
Red Blood Cell Count & 3.03 & $\times 10^{12} / \mathrm{L}$ & $4.3-5.5$ \\
Hematocrit & 25.5 & $\%$ & $36-46$ \\
Mean Cell Volume & 84.2 & $\mathrm{FL}$ & $80-97$ \\
Mean Cell Hemoglobin & 29.4 & $\mathrm{PG}$ & $27-33$ \\
Hemoglobin Consentration & 89 & $\mathrm{G} / \mathrm{L}$ & $120-150$ \\
Platelet Count & 225 & $\times 10^{9} / \mathrm{L}$ & $150-400$ \\
Mean Platlet Volume & 9.5 & $\mathrm{FL}$ & $7-11$ \\
Erythrocyte Sedimentation Rate & 40 & $\mathrm{~mm} / \mathrm{h}$ & $00-15$ \\
\hline
\end{tabular}


25.3-38.4). Hemoglobin electrophoresis showed HbS 58\%, $\mathrm{HbA} 36 \%, \mathrm{HbF} 2 \%$, and HbA2 4\% (consistent with sickle $\mathrm{b}$ thalassemia). Urine analysis was normal, and the culture report was negative. Magnetic Resonance Imaging (MRI) of the right orbit demonstrated peri-orbital edema and a mass adjacent to the right orbital wall. This condition was identified as a superior subperiosteal haematoma with evidence of orbital bone and bone marrow abnormal signals consistent with orbital wall infarction (Fig. 2).

The bone abnormality was further investigated to explore the possibility of the presence of primary or metastatic tumors that are susceptible to bleeding. Therefore, CT-imagery was utilized to explore this area of interest. However, as may be seen from the CT images, there was no evidence of primary or metastatic bone tumors (Fig. 3).

The patient received intravenous fluids, analgesics, broad spectrum antibiotics, and pulse methylprednisolone immediately. The patient responded well to medical management with complete recovery and was discharged after the condition was stabilized. This case has highlighted the importance of considering orbital wall infarction in the differential diagnosis of orbitopathy among the patients with SCD, along with osteomyelitis and orbital abscess. Careful evaluation, diagnosis, and the prompt initiation of the appropriate supportive care are highly recommended in order to prevent permanent visual loss.

\section{Discussion and conclusion}

SCD is the most common inherited hemoglobinopathy, which results from a point mutation (GAG/GTG) in

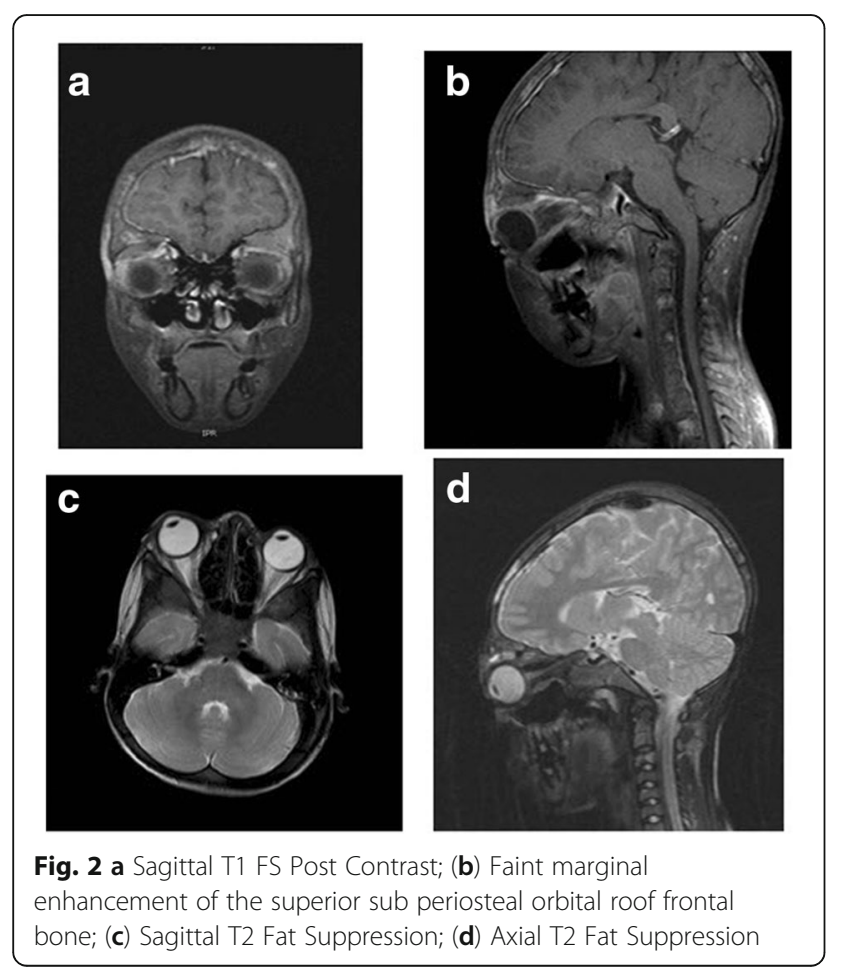

exon 1 of the $\beta$ globin gene. It results in the substitution of glutamic acid by valine at position 6 of the $\beta$ globin polypeptide chain. An abnormal hemoglobin $\mathrm{S}$ molecule is formed, which polymerizes under the conditions of hypoxia and acidosis. It will cause the red blood cell to become sickle in shape and rigid. These cells have short lifespan (chronic hemolysis) and tend to block capillaries (vaso-occlusion), which explains almost all clinical manifestations of SCD [15].

Orbital compression syndrome (OCS) is an acute condition characterized by eyelid edema, proptosis, periorbital pain, and restriction of extra-ocular motility, with or without decreased visual acuity. The main mechanism for the development of OCS is orbital bone infarction with subsequent inflammatory response that can rapidly spread to the orbit resulting in orbital pain and proptosis [6]. A unique feature of orbital wall infarction in SCD is the formation of hematomas, which may be orbital (subperiosteal) or intracranial (epidural) [8]. Several mechanisms have been suggested for the development of subperiosteal hemorrhage; such as extravasation of blood from necrotized vessel walls, underlying bleeding diathesis, and minor trauma [16]. Presumed cause of orbital hematoma in the present case is orbital infarction that was evident by abnormal frontal bone and bone marrow heterogeneous signals adjacent to the formation of hematomas.

Orbital wall infarction typically occurs among young patients because there is more marrow space in the orbital bone among children, unlike the adults [16]. The mean age of presentation in the reported cases was 13 years, with the youngest reported age at 2 years. It affects almost twice as many males as females. The OCS has wide spectrum of manifestations ranging from its mild form which constitutes pain and eyelid edema to the most severe of bilateral proptosis, chemosis, limited ocular motility, and vision loss. Fever at presentation occurs in almost all cases, and associated pain crises elsewhere were seen in more than two thirds of the cases. Bilateral orbital involvement was reported in one third of cases [7]. The differential diagnosis of acute periorbital pain and swelling with or without other manifestations of OCS in patients with SCD include orbital cellulitis, orbital abscess, pre-orbital cellulitis, osteomyelitis of orbital bone, orbital tumor and orbital bone infarction.

It is crucial and challenging to differentiate between orbital bone infarction and orbital osteomyelitis, and the presence of Leukocytosis and elevated erythrocyte sedimentation rate as $\mathrm{C}$-reactive protein can occur in both bone infection and infarction [17]. Bone marrow abnormalities are well documented by MRI as well as orbital soft-tissue swelling, sub-periosteal hemorrhage, and fluid collections. MRI showed the location, size, and effects of 

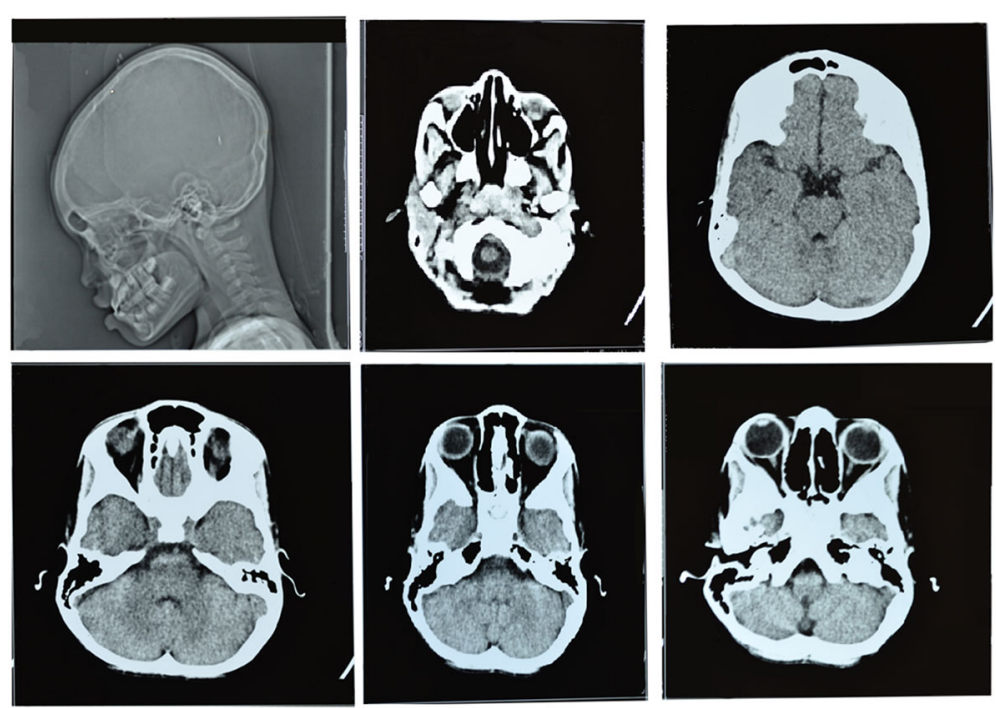

Fig. 3 CT scan images of subperiosteal orbital bone abnormality

the hematoma on the adjacent orbital structures including the optic nerve. The presence of abnormal MRI signals indicated acute inflammatory process in the area of the orbital roof and bone marrow of the frontal bone in the present case. Bone marrow scan confirms marrow infarction in $95 \%$ of cases by demonstrating decreased tracer uptake; whereas, in infection the uptake is normal. MRI was the imaging modality of choice for evaluating OCS in majority of the reported cases. [17].

The present case is unique because the condition is recurrent in the frontal bone, triggered by visit to a high-altitude city. Similar studies pertaining to infarctions in SCD at high-altitude areas have been conducted; however, this is the first study to conduct an exploration of orbital bone infarction in SCD at high-altitude areas $[10,13]$. However, previously OCS attacks had resolved completely with conservative measures. Administration of intravenous corticosteroids may relieve orbital pressure, caused by inflammatory component of orbital bone infarction. Concomitant antibiotic coverage is advisable as it is often difficult to clinically differentiate osteomyelitis from bone infarction. Surgical exploration and evacuation of hematoma is warranted to prevent vision loss and speedy recovery, if there are signs of optic nerve dysfunction. Majority of the reported patients recovered with medical therapy, and around one fifth of these patients required surgical interventions. Two of the reported cases ended with permanent visual loss because of optic nerve compression [8]. Clinical optic nerve dysfunction, significant eye globe displacement, and thinning and touristy of optic nerve on MRI were considered as poor prognostic signs. Surgical intervention and draining of hematomas should be performed, once the patient demonstrates signs of optic nerve compression that poorly respond to conservative management.

The diagnosis of OCS should be considered, when patients with SCD complain of proptosis, decreased extra ocular motility, eyelid edema, and optic neuropathy. Children with SCD are susceptible to infections, and empirical use of broad spectrum antibiotics should be considered, if infectious process is suspected. Imaging techniques are essential in the evaluation of patients, suffering osteomyelitis and orbital abscess. Majority of cases resolve with conservative treatment that includes hydration and oxygen to reverse the vaso-occlusive crisis and use of systemic steroids under antibiotic cover. Critical evaluation and prompt surgical intervention is needed to prevent loss of vision, if evidence of optic nerve dysfunction or large hematoma is present.

\section{Abbreviations}

APD: Afferent pupillary light reflex defect; MRI: Magnetic Resonance Imaging; OCS: Orbital compression syndrome; SCD: Sickle cell disease

\section{Acknowledgements}

The author is very thankful to all the associated personnel that contributed in/for the purpose of this research. Dr. Magdy Hazza, MD, FRCS senior consultant ophthalmologist, Professor Abdullhamid Serwah senior academic staff, faculty of medicine and Dr. Naglaa Fawazy Radiology consultant.

\section{Funding}

Taif University, Faculty of Medicine.

\section{Availability of data and materials}

The datasets used and analysed during the current study are available from the corresponding author on reasonable request.

\section{Authors' contributions}

The author has solely contributed for this case report, and the author approved this final version to be published.

Competing interest

The author declares no competing interest. 
Ethics approval and consent to participate

Not applicable.

\section{Consent for publication}

Written informed consent was obtained from parent of the patient for publication of this article and any accompanying tables \& images. A copy of the written consent is available for review by the Editor of this journal.

\section{Publisher's Note}

Springer Nature remains neutral with regard to jurisdictional claims in published maps and institutional affiliations.

Received: 6 October 2017 Accepted: 14 August 2018

Published online: 28 August 2018

\section{References}

1. Bello-Manga H, DeBaun MR, Kassim AA. Epidemiology and treatment of relative anemia in children with sickle cell disease in sub-Saharan Africa. Expert Rev Hematol. 2016;9:1031-42. https://doi.org/10.1080/17474086.2016. 1240612.

2. Al-Qurashi MM, El-Mouzan MI, Al-Herbish AS, Al-Salloum AA, Al-Omar AA. The prevalence of sickle cell disease in Saudi children and adolescents. A community-based survey. Saudi Med J. 2008;29:1480-3.

3. Frisancho OE, Ichiyanagui RC. Spleen infarction and hemoglobinopathies $\mathbf{S}$ in the high altitude lands. Rev Gastroenterol Peru. 2012;32:68-78.

4. Pincez T, Calamy L, Germont Z, Lemoine A, Lopes AA, Massiot A, Tencer J, Thivent C, Hadchouel A. Pulmonary complications of sickle cell disease in children. Arch Pediatr. 2016;23:1094-106.

5. Emerson $G G$, Lutty GA. Effects of sickle cell disease on the eye: clinical features and treatment. Hematol Oncol Clin North Am. 2005;19:957-73. https://doi.org/10.1016/j.hoc.2005.07.005.

6. Sokol JA, Baron E, Lantos G, Kazim M. Orbital compression syndrome in sickle cell disease. Ophthal Plast Reconstr Surg. 2008;24:181-4. https://doi. org/10.1097/iop.0b013e31816b960e.

7. Ganesh RR, William S, Mitra S, Yanamadala SS, Hussein S, Al-Kindi S. Orbital involvement in sickle cell disease: a report of five cases and review literature. Eye. 2001;15:774-80. https://doi.org/10.1038/eye.2001.248.

8. Ghafouri RH, Lee I, Freitag SK, Pira TN. Bilateral orbital bone infarction in sickle-cell disease. Ophthal Plast Reconstr Surg. 2011;27:26-7. https://doi.org/ 10.1097/iop.0b013e3181c70b65

9. Piel FB, Tewari S, Brousse V, Analitis A, Font A, Menzel S, Chakravorty S, Thein SL, Inusa B, Telfer P, de Montalembert M, Fuller GW, Katsouyanni K, Rees DC. Associations between environmental factors and hospital admissions for sickle cell disease. Haematology. 2016;15:42-5. https://doi. org/10.3324/haematol.2016.154245.

10. Adzaku F, Addae S, Annobil S, Mohammed S. Clinical features of sickle cell disease at altitude. J Wilderness Med. 1992;3(3):260-8. https://doi.org/10. 1580/0953-9859-3.3.260.

11. Green RL, Huntsman RG, Serjeant GR. The sickle-cell and altitude. Br Med J. 1971:4(5787):593-5. https://doi.org/10.1136/bmj.4.5787.593.

12. Godwin MJ, Embury SH, Claster S. Risk of altitude exposure in sickle cell disease. West J Med. 1981;135(5):364.

13. Habibzadeh S, Maleki N. Sickle cell trait at high altitude. Int J Crit IIIn Inj Sci. 2015;5(2):129. https://doi.org/10.4103/2229-5151.158428.

14. Cheong HI, Janocha AJ, Monocello LT, Garchar AC, Gebremedhin A, Erzurum SC,Beall CM. Alternative hematological and vascular adaptive responses to high-altitude hypoxia in East African Highlanders. Am J Physiol Lung Cell Mol Physiol. 2016;15:Epub a head of print. Doi: https://doi.org/10. 1152/ajplung.00451.2016

15. Serjeant GR. The natural history of sickle cell disease. Cold Spring HarbPerspect Med. 2013;3:a011783. Review. https://doi.org/10.1101/ cshperspect.a011783.

16. Janssens $C$, Claeys L, Maes P, Boiy T, Wojciechowski M. Orbital wall infarction in child with sickle cell disease. Acta Clin Belg. 2015;70:451-2. https://doi. org/10.1179/2295333715y.0000000053.

17. Naoko S, NadgirRohini N, Flower Elisa N, Osamu S. Clinical and radiologic manifestations of sickle cell disease in the head and neck. Radio Graph. 2010;30:1021-35. https://doi.org/10.1148/rg.304095171.

Ready to submit your research? Choose BMC and benefit from:

- fast, convenient online submission

- thorough peer review by experienced researchers in your field

- rapid publication on acceptance

- support for research data, including large and complex data types

- gold Open Access which fosters wider collaboration and increased citations

- maximum visibility for your research: over $100 \mathrm{M}$ website views per year

At BMC, research is always in progress.

Learn more biomedcentral.com/submissions 